\title{
TRIANGULATION AND TIME-OF-FLIGHT BASED 3D DIGITISATION TECHNIQUES OF CULTURAL HERITAGE STRUCTURES
}

\author{
C. Altuntas ${ }^{1} *$ \\ ${ }^{1}$ Konya Technical University, Faculty of Engineering and Natural Sciences, 42250 Selcuklu, Konya, Turkey - \\ caltuntas@ktun.edu.tr
}

KEY WORDS: 3D Measurement, Modelling, Optic Measurement, Cultural Heritage Documentation, Point Cloud

\begin{abstract}
:
This study aims to introduce triangulation and ToF measurement techniques used in three-dimensional modelling of cultural heritages. These measurement techniques are traditional photogrammetry, SfM approach, laser scanning and time-of-flight camera. The computer based approach to photogrammetric measurement that is named SfM creates dense point cloud data in a short time. It is low-cost and very easy to application. However traditional photogrammetry needs a huge effort for creating 3D wire-frame model. On the other hand active measurement techniques such as terrestrial laser scanner and time-of-flight camera have also been used in three-dimensional modelling for more than twenty years. Each one has specific accuracy and measurement effectiveness. The large or small structures have different characters, and require proper measurement configurations. In this study, after these methods are introduced, their superior and weak properties in cultural heritage modelling to make high accuracy, high density and labour and cost effective measurement.
\end{abstract}

\section{INTRODUCTION}

Many active and passive non-contact three-dimensional (3D) measurement techniques have been practised to measuring cultural heritage objects so far. Innovations in the image-based measurement techniques are largely related to developments on computer and data processing technology. The developments which have instrumental innovations offer high accuracy and density measurement in a short time, but probably with the high price. On the other hand some techniques have on-site and the others have post processes measurement data. The measurement techniques can be classified in two categories as time-of-flight and triangulation based or active and passive techniques.

3D modelling of cultural heritage is prevalent application area for 3D measurement (Remondino, 2011; Sansoni et al., 2009). The object surface is digitized with particular space of points for 3D modelling the object in computer environment. The high density points represent the object surface with close to real shape. Low density point cloud is lack of real visualization of the surfaces. Traditional photogrammetry creates wireframe 3D model with lines. Thus, many object characteristics are ignored in this measurement (Tobiasz et al., 2019). However new instruments are enabling to make measurement with high density points in a short time by triangulation or time-of-flight techniques (Adamopoulos et al., 2021).

The automatic image matching by using SfM algorithm enables high density photogrammetric measurement. Moreover, it does not need any technical knowledge to perform the measurement task. Thus it is exploited for many aims such as topography mapping, object modelling, medical imaging, crime scene visualization and etc (Huang et al., 2020; Previtali et al., 2014). Aicardi et al. (2018) declared that the photogrammetry and computer vision approach techniques in choice of cultural heritage digitization should be selected according to object size and measurement aims. Time of flight laser scanning (Grussenmeyer et al., 2015; Sanchez-Aparicio et al., 2019) and range cameras (Chiabrando et al., 2011) are also used in 3D measurement tasks depend of their measurement characteristics such as range, accuracy, point density and cost. On the other hand, especially, documentation of cultural heritage which has complex shape needs to use multi sensor 3D measurement techniques (Balletti and Ballarin, 2019; Murtiyoso et al., 2018; Ramos and Remondino, 2015). The cultural heritage objects have usually large-scale and complex shape. The 3D modelling of cultural heritage objects should be performed with proper measurement technique to get enough accuracy. In addition the object virtual realization to close the real image requires high density point cloud data from the surface. The aim of this study is analyse the measurement techniques used in $3 \mathrm{D}$ digitization of historical objects, and show acquired experimental results.

\section{TIME-OF-FLIGHT MEASUREMENT}

The range measurement is performed with laser flight time in the time-of-light measurement techniques. The object coordinates are acquired according to instrument based locally coordinate frame. At this local system, direction of the measured object point is defined with horizontal and vertical angles or image coordinates. Terrestrial laser scanner and timeof-flight camera are two active measurement techniques.

\subsection{Laser scanning}

Time-of-flight laser scanners use pulse and phase-shift methods to measuring the ranges. Pulse-based laser scanner uses light travel time to getting distance from instrument to object. The flying path interaction of the light affects the measurement accuracy on this method. The maximum measurement distance to the pulse based laser scanners reaches about six kilometres. The measured distance $(r)$ depends time interval between emitted and received signals and formulated as Equation (1)

$$
r=c . \Delta t / 2
$$

The measurement accuracy is highly dependent to flight time of the light. Accordingly, in order to get one millimetre accuracy 
to the range, the flight time $(\Delta t)$ of the light should be determined with a precise of 6.67 picoseconds. The range uncertainty $\left(\sigma_{r}\right)$ for a single pulse is given by the following equation (Beraldin, 2004):

$$
\sigma_{r}=\frac{c \cdot T_{r}}{c \sqrt{S N R}}
$$

$T_{r}:$ pulse rise time

SNR : Signal noise ratio $(\mathrm{SNR}=100)$

The phase shift method uses phase difference between reflected and received signals. The time-of-flight of the laser light from the sensor to object and back results directly in a phase difference between transmitted and received laser light. The phase difference is proportional to range and laser modulation frequency (Elkhrachy, 2008). To get the object distance, number of full wavelengths and rest of the wavelength should be defined. It is not possible to get the object distance from a simple AMCW (amplitude-modulated continuous wave) ranging method. To get around the inconvenience of a range ambiguity interval, one can use multiple frequency waveforms. The accuracy of phase-shift ranging method is affecting from modulation frequency, signal strength and scan air condition. The maximum measurement distance is about six hundred meters in phase-shift laser scanners.

The laser scanner collects range $(r)$, intensity $(I)$ and orientation angles $(\alpha, \theta)$ of a scan point together with colour $(R, G, B)$ camera images. 3D coordinates $(X, Y, Z)$ are then generated from them (Figure 1). Beam divergence and angular step resolution are two basic properties to define the spatial resolution of the measured scan points. Their incompatible values create uncertainty to measured point position. Large beam divergence creates large spot to the scan point. The phase shift laser scanners have small beam divergence that enable to measure high density spatial data with the high accuracy than pulse-based scanners. Because TLS is ground based instrument, the complicated shapes can not be measured by them completely.

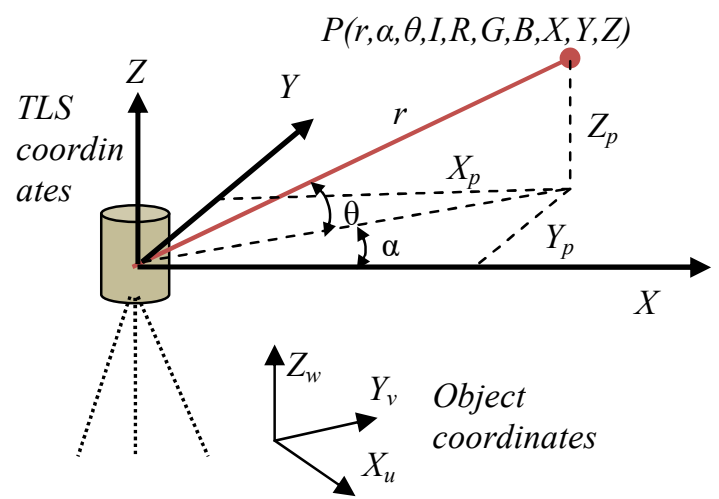

Figure 1. Laser scanner measurements and coordinates.

\subsection{Solid-state time-of-flight camera}

ToF camera measurement principle is similar to imaging system of a pinhole camera. A single signal is sent from the optical centre to the object surface, and distances from matrix-shaped pixels to the corresponded object points are measured simultaneously by using the AMCW method (Figure 2). ToF camera has short measurement distance (around $5 \mathrm{~m}$ ) and capable to very fast measurement. It collects more than 60 frames at per second. It has small dimensions and light weight that enables to hand-held mobile measurement. All details can be imaged moving the camera by hand around the object. ToF camera measurement accuracy is very sensitive to lighting conditions and surface reflectivity. Thus the measurement accuracy is around $1 \mathrm{~cm}$ at their maximum range.

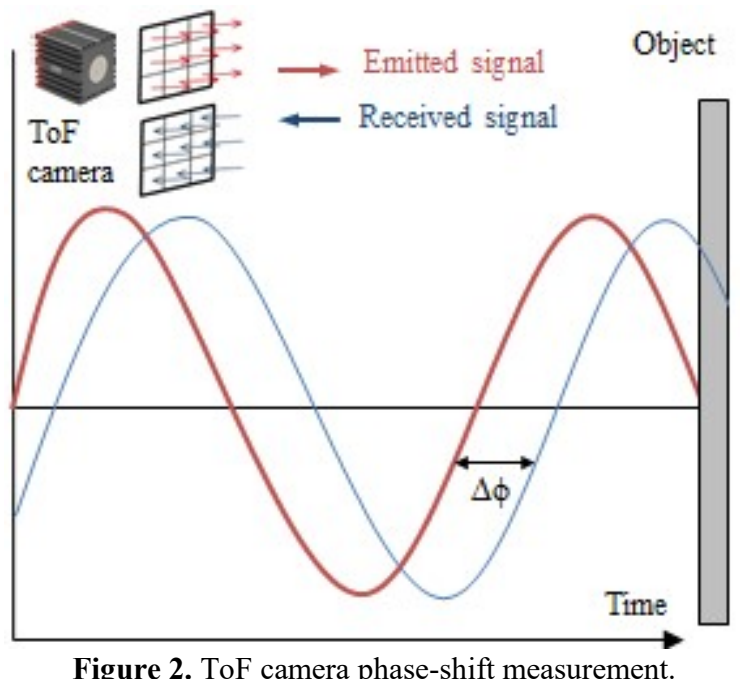

To get a complete 3D model of the surveyed objects, more acquisition from different fixed point of view is usually required with ToF cameras. In addition, camera positions are adopted as overlap of about $40 \%$ on surveying the entire object. Since each point cloud is referred to a local coordinate system fixed to the ToF camera, proper registration methods have to be adopted in order to register the acquired data to selected reference frame. The ToF camera is acquired several frames of a static scene with its a stable position. The average of the acquired frames is estimated in order to reduce the measurement noise. The ToF camera measurement data are often resultant with noisy characterized by several systematic and random errors, which have to be reduced in order to allow the use of ToF cameras for metric survey purposes (Chiabrando et al., 2011).

\section{TRIANGULATION MEASUREMENT}

A triangulation is constituted to get the measured object distance from the instrument. One of the triangulation corners is object point, and the others are positioned with two cameras or camera and laser combination. The laser included instrument is called as active triangulation otherwise passive triangulation. The scale to the measurement data is attained by the control points or scale bar measured on the object in passive triangulation. If the camera and laser are on the same compact instrument, the measurement data is scaled with the base length between the camera and laser source. The control points are used to obtain the scale when the camera and laser source does not have a compact design.

\subsection{Stereo photogrammetry}

The close-range photogrammetry is extensively used for documentation of cultural heritage as wireframe digitization. The wireframe digitization is drawing the line to object significant details. A line is generated in stereo area via selecting the corresponding points from the images. 
Three-dimensional spatial data in close-range photogrammetry are estimated by intersecting the imaging line from two projection centres. Their mathematical model is named collinearity condition that means projection centre, image and object points are on the same line (Figure 3). The same object point selection from two images requires more labour and time. A line in stereo area is generated via selecting the corresponding points from the images. A wireframe 3D model represents only main shape to the measured object. The line generation for small detail is very hard (Figure 4). The measurement accuracy depends to unknown variables on the collinearity equation. The unknown variables are image coordinates, image orientation parameters, focal length and distortion parameters. In addition, the accuracy is largely related to base-to-height ratio. The spatial accuracy for a point is a few centimetres under the ideal conditions.

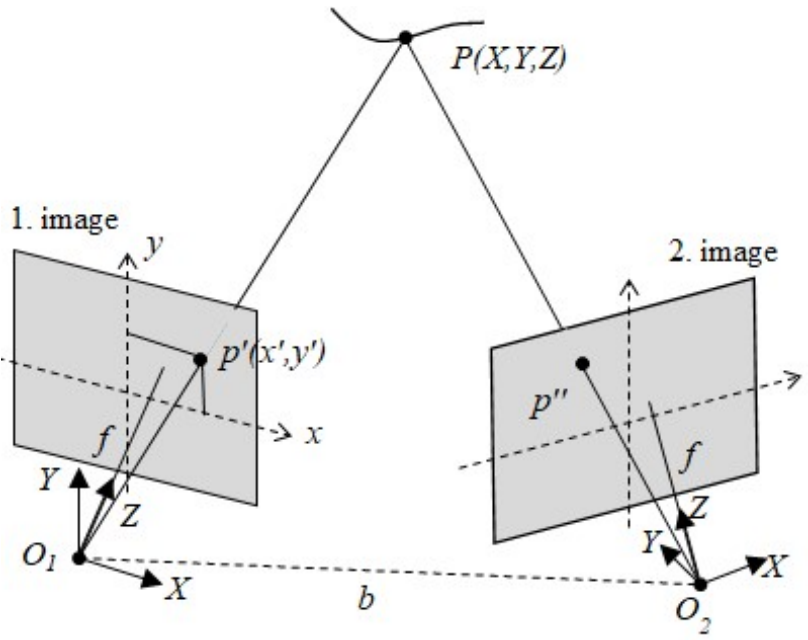

Figure 3. Stereo image triangulation

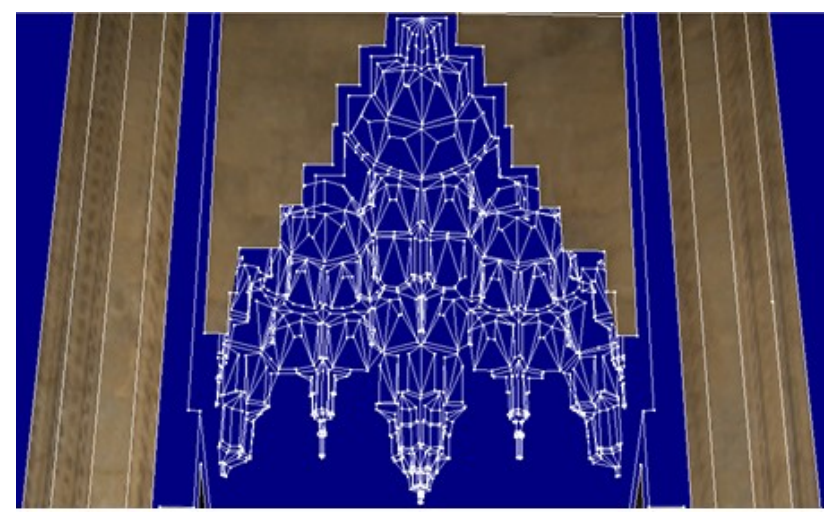

Figure 4. Photogrammetric wireframe 3D model (Altuntas et al., 2019).

\subsection{Dense matching photogrammetry}

The corresponding points are constituted as automatically by matching similar features from the images in dense matching of stereo images. Three-dimensional coordinates are estimated for the matched feature points using photogrammetry principles. These object coordinates constitute the sparse point cloud that has nonuniform point spaces. Dense point cloud that has uniform point spaces are then generated with more matching by the estimated exterior image parameters. Automatic image matching and point cloud creation procedures are collectively called as structure-from-motion (SfM) algorithm (Granshaw,
2018). The SfM algorithm can also be realized without camera calibration parameters. Nevertheless, the lack of complete camera calibration and the absence of a perspective bundle adjustment with all the recovered parameters militate against an accurate reconstruction by photogrammetry (Barazzetti et al., 2010). SfM based measurement can be applied easily without any technical knowledge about the evaluation. It has been practised for many 3D measurement tasks such as object modelling, object tracking, computer vision etc. Although traditional photogrammetry need stereo image in suitable conditions for high accuracy, overlapping images or imageries from any sources can be evaluated in SfM measurement. Complex shapes of cultural heritages can be modelled with SfM based evaluation of several images taken from different point of view.

Today, commercial photogrammetry software generates 3D point cloud by proceeding SfM algorithm with a fewer user interactions. The derived sparse point clouds need extensive editing operations to produce a complete and textured 3D model, in particular for cultural heritage 3D reconstructions. The project scale can be attained by coded targets to the generated 3D sparse or dense point cloud model. The point cloud is generally transformed into a polygonal mesh model for texturing and $3 \mathrm{D}$ visualisation.

\subsection{Triangulation scanner}

Triangulation laser scanner uses laser light and CCD camera to probe the environment. A laser beam at a defined incrementally changed angle is sending onto the object and, CCD camera, which was integrated based distance away, detects the laser spot on the object. This means the range between object and laser scanner within limited range $(r)$ is based on optical triangulation (Figure 5). The 3D location of a laser point on the surface can be derived from the resulting triangle. The distance between the camera and the laser emitter is known base $(b)$. The angle $(\theta)$ of the laser emitter corner and derived laser spot image coordinates is also known. These three known information figure the location of the laser dot which is corner of the triangle. In most cases a laser stripe, instead of a single laser dot, is swept across the object to speed up the acquisition process. Furthermore, object surface at the point of view is measured instantly by reflecting coded light. The coded laser scanner is very fast and can also make mobile measurement.

The maximum range depends the base length at this system. The base length is about $15 \mathrm{~cm}$ and thus maximum range is around $8 \mathrm{~m}$ (Beraldin et al., 2000). The range measurement accuracy is very high and millimetre level for the instruments. It is uniquely favourable for digitization of small dimension cultural objects. The scan as stripe is usually performed with turntable the object on it.

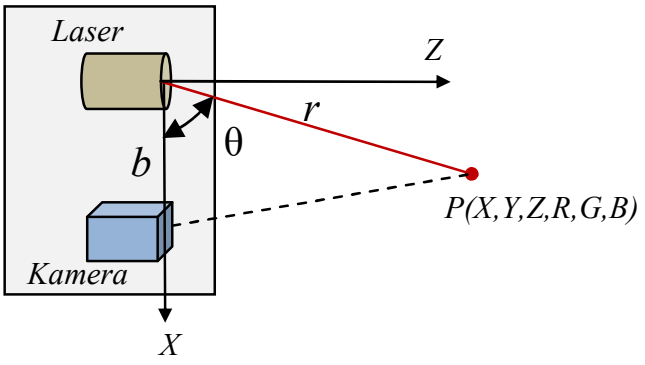

Figure 5. Principal of active triangulation scanner. 


\section{RESULTS AND DISCUSSION}

In order to fully documentation of historical buildings, all the details must be viewed and measured. The wireframe 3D model is generated by stereo photogrammetry and, represents the details of the object in the form of lines. However, measurement data of laser scanning and SfM is point cloud (Figure 6). The high density point cloud data represents the shape of small object details with close to real visualization. In this respect, the most successful measurement methods are laser scanners and SfM. Especially, the triangulation laser scanner generates high density point cloud data in its available short measurement distance. In addition, it provides high accuracy at millimetre level. The measurement accuracy for all of the methods is decreased by the distance increased.
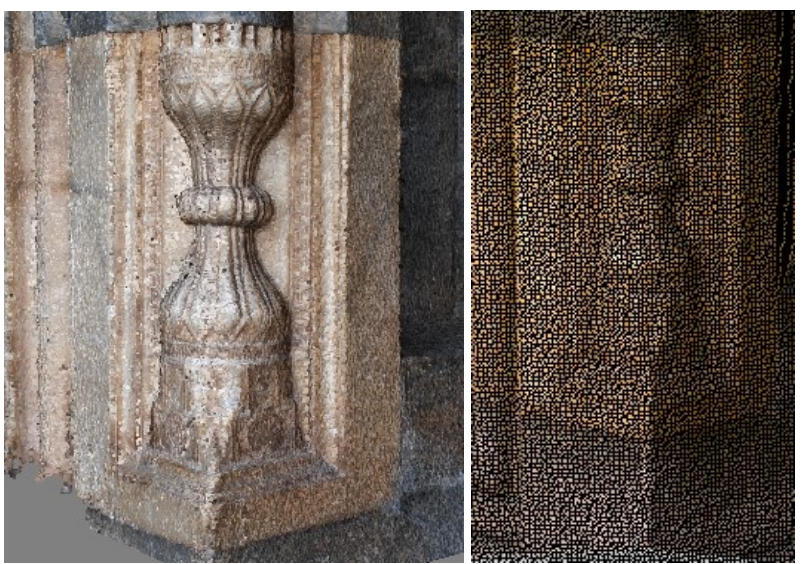

Figure 6. 3D visualization by SfM (on the left) and TLS point clouds.

The costs of time-of-flight laser scanners are quite high. ToF cameras are inexpensive and slightly higher cost than CCD cameras. ToF camera is widely used in mobile measurement in addition to measuring cultural heritage (Figure 7). Generally, passive measurement methods are considered as low cost.

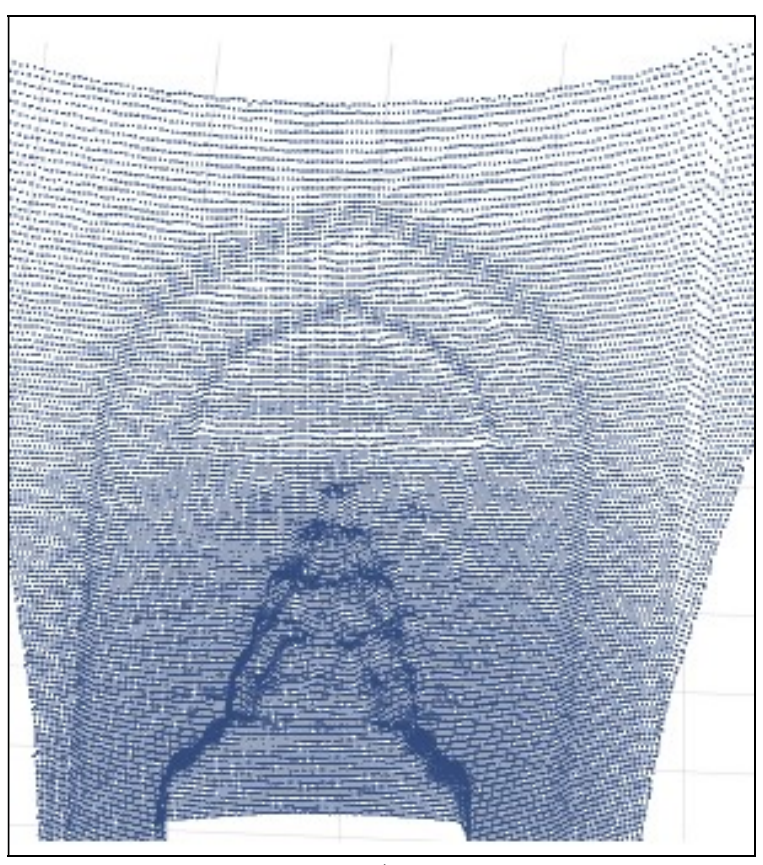

a)

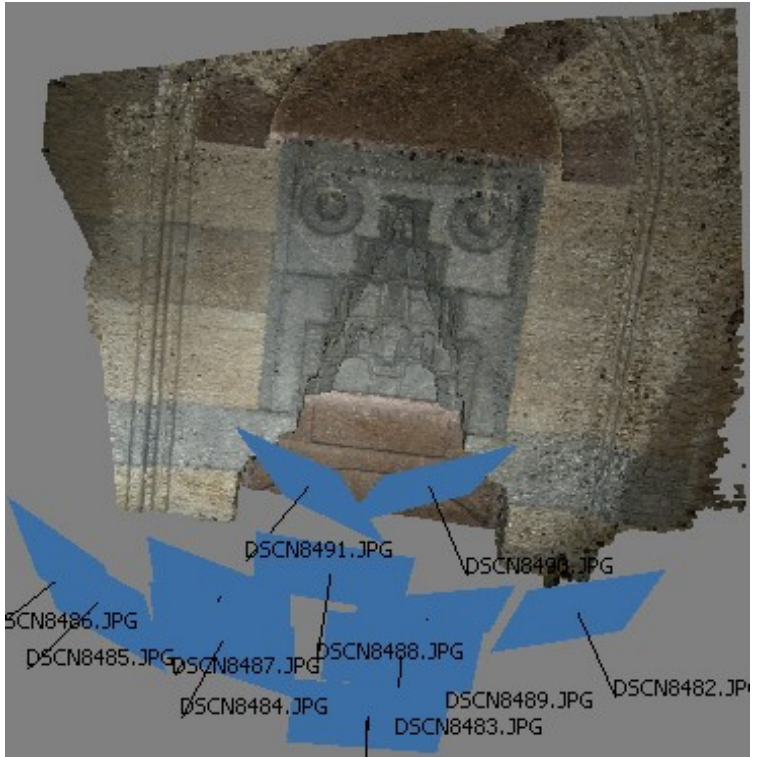

b)

Figure.7. a) ToF camera measurement data, b) SfM approach point cloud.

Unlike stereo photogrammetry which requires intensive labour and knowledge about the processes to get measurement data, SfM method can be executed without even any technical knowledge.

Because the laser scanners are ground-based instrument, many occlusions are occurred to point cloud data of complex structure. However, all of the details can be viewed by handheld time-of-flight or CCD camera. In this respect, photogrammetry is a measurement method complementary to laser scanning in 3D modelling of cultural heritage (Table 1).

\begin{tabular}{|c|c|c|c|c|c|}
\hline & $\begin{array}{l}\text { Stereo } \\
\text { photog } \\
\text { ramme } \\
\text { try }\end{array}$ & SfM & $\begin{array}{l}\text { ToF } \\
\text { camera }\end{array}$ & $\begin{array}{l}\text { ToF } \\
\text { laser } \\
\text { scanner }\end{array}$ & $\begin{array}{l}\text { Triang. } \\
\text { laser } \\
\text { scanner }\end{array}$ \\
\hline $\begin{array}{l}\text { On-site } \\
\text { work }\end{array}$ & $\begin{array}{l}\text { Very } \\
\text { short }\end{array}$ & $\begin{array}{l}\text { Very } \\
\text { short }\end{array}$ & Short & Short & Short \\
\hline $\begin{array}{l}\text { 3D } \\
\text { data } \\
\text { acquisi } \\
\text { tion } \\
\text { time } \\
\end{array}$ & Long & Short & $\begin{array}{l}\text { Very } \\
\text { short }\end{array}$ & Short & Short \\
\hline $\begin{array}{l}\text { Data } \\
\text { acquisi } \\
\text { tion }\end{array}$ & $\begin{array}{l}\text { Post } \\
\text { process } \\
\text { es }\end{array}$ & $\begin{array}{l}\text { Post } \\
\text { processes }\end{array}$ & On site & On site & On site \\
\hline $\begin{array}{l}\text { Accur } \\
\text { acy }\end{array}$ & $\begin{array}{l}1 \mathrm{~cm} @ \\
10 \mathrm{~m}\end{array}$ & $\begin{array}{l}1 \mathrm{~cm} @ 10 \\
\mathrm{~m}\end{array}$ & $\begin{array}{l}1 \mathrm{~cm} @ 5 \\
\mathrm{~m}\end{array}$ & $\begin{array}{l}1 \mathrm{~cm} @ 10 \\
\mathrm{~m}\end{array}$ & $\begin{array}{l}<1 \mathrm{~cm} @ \\
7 \mathrm{~m}\end{array}$ \\
\hline $\begin{array}{l}\text { 3D } \\
\text { data }\end{array}$ & $\begin{array}{l}\text { Line, } \\
\text { point }\end{array}$ & $\begin{array}{l}\text { Point } \\
\text { cloud }\end{array}$ & $\begin{array}{l}\text { Point } \\
\text { cloud }\end{array}$ & $\begin{array}{l}\text { Point } \\
\text { cloud }\end{array}$ & $\begin{array}{l}\text { Point } \\
\text { cloud }\end{array}$ \\
\hline $\begin{array}{l}\mathrm{CP} \\
\text { requir } \\
\text { ement }\end{array}$ & Yes & Yes & No & No & No \\
\hline Cost & Low & Low & Medium & High & High \\
\hline $\begin{array}{l}\text { Labou } \\
\text { r }\end{array}$ & High & Low & Low & Low & Low \\
\hline $\begin{array}{l}\text { Max. } \\
\text { range }\end{array}$ & $>100 \mathrm{~m}$ & $>100 \mathrm{~m}$ & $5 \mathrm{~m}$ & $\begin{array}{l}600 \mathrm{~m} \\
\text { (phase- } \\
\text { shift) } \\
6 \mathrm{~km} \\
\text { (pulse) }\end{array}$ & $7 \mathrm{~m}$ \\
\hline
\end{tabular}

Table 1. The summarized properties of triangulation and $\mathrm{ToF}$ measurement techniques in cultural heritage documentation. 
The acquired point cloud of laser scanning and SfM do not have colour data. Their high density point cloud visualise the object in digital environment. However ToF camera does not have any colour information. Thus only significant geometrical changes can be selected from its point cloud. An intensity image should be created with reflectance of the measurement for selecting the object details. Otherwise, a CCD camera must be integrated and configured to the ToF camera.
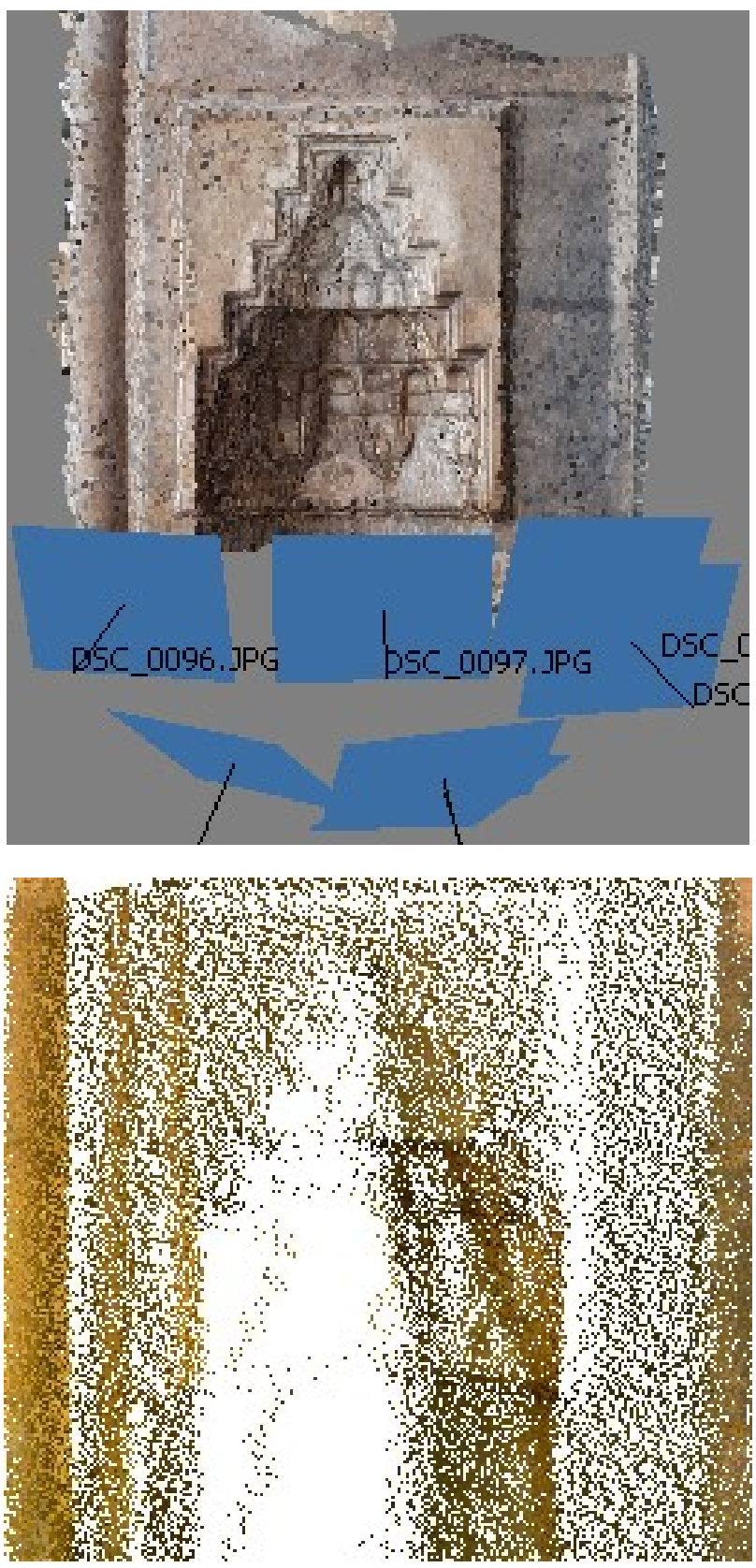

Figure 8. Dense image matching point cloud model (on the top), and laser scanning point cloud model with occlusion that was not imaged by TLS.

The virtual realization requires mapping the image texture data onto the $3 \mathrm{D}$ point cloud. At first, mesh surface is constituted from the point cloud. The occlusions of the point cloud should be removed for uniform triangulation (Figure 8). Though the small occlusions can be filled by interpolating from neighbour spatial data, the large occlusions must be removed by integrating the point cloud of the other measurement methods. Then texture data is mapped from overlapping area to stereo images in photogrammetry. However laser scanner and ToF camera needs external images for texturing of their point clouds.

\section{CONCLUSION}

The laser scanning is a suitable method to measure a large scale and small shape historical structures. Nevertheless some structures that have complex shapes could not be measured by laser scanner. Thus the SfM algorithm or ToF camera can be exploited to complete the occlusion parts by generating point cloud. Consequently, none of these measurement methods are separately suitable for measuring in every size and shape cultural structures. The cultural heritage documentation may require using a combination of these methods to achieve full $3 \mathrm{D}$ documentation.

\section{REFERENCES}

Adamopoulos, E., Rinaudo, F., Ardissono, L. 2021. A critical comparison of 3D digitization techniques for heritage objects. ISPRS Int. J. Geo-Inf., 10(1), 10.

Altuntas, C., Mert, S., Yaman, G., Cengiz, Y., Sonmez, M., 2019. Photogrammetric wireframe and dense point cloud 3D modelling of historical structures: The study of Sultan Selim Mosque and Yusuf Aga Library in Konya, Turkey. Int. Arch. Photogramm. Remote Sens. Spatial Inf. Sci., XLII-2/W11, 7782, doi.org/10.5194/isprs-archives-XLII-2-W11-71-2019.

Aicardi, I., Chiabrando, F., Lingua, A., Noardo, F., 2018. Recent trends in cultural heritage 3D survey: The photogrammetriccomputer vision approach. Journal of Cultural Heritage 32, 257-266.

Balletti, C., Ballarin, M., 2019. An application of integrated 3D technologies for replicas in cultural heritage. ISPRS Int. J. GeoInf., 8(6), 285.

Barazzetti, L., Scaioni, M., Remondino, F., 2010. Orientation and 3D modelling from markerless terrestrial images: Combining accuracy with outomation. The Photogrammetric Record 25(132), 356-381.

Beraldin, J. A., 2004. Integration of laser scanning and closerange photogrammetry - the last decade and beyond. Int. Arch. Photogramm. Remote Sens. Spatial Inf. Sci., XXXV/B5, 972983.

Beraldin, J.A., Blais, F., Cournoyer, L., Godin, G., Rioux, M., 2000. Active 3D sensing. Centro di Ricerche Informatiche per $i$ Beni Culturali Scuola Normale Superiore Pisa Quaderni 10, http://www1.cs.columbia.edu/ allen/PHOTOPAPERS/beraldin. pdf.

Chiabrando, F., Piatti, D., Rinaudo, F., 2011. New sensors for cultural heritage metric survey: The ToF cameras. Geoinformatics FCE CTU 6, 360-313.

Elkhrachy, I., 2008. Towards an automatic registration for terrestrial laser scanner data. $\mathrm{PhD}$ Thesis. Technischen Universit at Carolo-Wilhelminazu Braunschweig. 
Granshaw, S. I., 2018. Structure from motion: Origins and originality. The Photogrammetric Record 33(161), 6-10.

Grussenmeyer, P., Alby, E., Assali, P., Poitevin, V., Hullo, J.F., Smigiel, E., 2015. Accurate documentation in cultural heritage by merging TLS and high resolution photogrammetric data. Proc. of SPIE, 8085, 808508.

Huang, F., Yang, H., Tan, X., Peng, S., Tao, J., Peng, S., 2020. Fast reconstruction of $3 \mathrm{D}$ point cloud model using visual SLAM on embedded UAV development platform. Remote Sensing 12(20), 3308.

Murtiyoso, A., Grussenmeyer, P., Suwardhi, D., Awalludin, R., 2018. Multi-scale and multi-sensor 3D documentation of heritage complexes in urban areas. ISPRS Int. J. Geo-Inf., 7(12), 483.

Previtali, M., Barazzetti, L., Scaioni, M., 2014. Accurate 3D surface measurement of mountain slopes through a fully automated image-based technique. Earth Science Informatics 7(2), 109-122.

Ramos, M.M., Remondino, F., 2015. Data fusion in cultural heritage- A review. The International Archives of the Photogrammetry, Remote Sensing and Spatial Information
Sciences, XL-5/W7, 359-363, doi:10.5194/isprsarchives-XL-5W7-359-2015.

Remondino, 2011. Heritage recording and 3D modeling with photogrammetry and 3D scanning. Remote Sensing 3, 11041138.

Sanchez-Aparicio, L.J., Conde, B., Mate-Gonzalez, M. A., Mora, R., Sanchez-Aparicio, M., Garcia-Alvarez, J., GonzalezAguilera, D., 2019. A comparative study between WMMS and TLS for the stability analysis of the San-Pedro Church Barrel Vault by means of the finite element method. Int. Arch. Photogramm. Remote Sens. Spatial Inf. Sci., XLII-2/W15, 1047-1054, doi.org/10.5194/isprs-archives-XLII-2-W15-10472019.

Sansoni, G., Trebeschi, M., Docchio, F., 2009. State-of-the-art and applications of 3D imaging sensors in industry, cultural heritage, medicine, and criminal investigation. Sensors 9, 568601.

Tobiasz, A., Markiewicz, J., Łapiński, S., Nikel, J., Kot, P., Muradov, M. 2019. Review of methods for documentation, management, and sustainability of cultural heritage. Case study: Museum of King Jan III's Palace at Wilanów. Sustainability 11(24), 7046. 